\title{
El feminismo sufragista: entre la persuasión y la disrupción
}

\author{
Dennyris Castaño Sanabria \\ Universidad de Granada, Granada, España. \\ Email: dennyris@correo.ugr.es
}

\begin{abstract}
Resumen: Este artículo presenta una revisión de los aportes que el movimiento sufragista realiza a los métodos de lucha no armada a finales del siglo XIX y principios del siglo XX. Hace un análisis de la relación entre estos métodos de lucha y los objetivos perseguidos, estableciendo matices entre las opciones de lucha de suffragists y suffragettes. Igualmente, pretende hacer una comparación entre lucha sufragista y «resistencia pasiva», más allá de la distinción hecha en el artículo escrito por Gandhi sobre Satyagrahavs. «resistencia pasiva».

Palabras clave: sufragismo, medios-fines, resistencia pasiva, satyagraha.
\end{abstract}

\section{Women's suffrage movement: amongst persuasion and disruption}

\begin{abstract}
This article presents an overview of the contributions of the suffrage movement to the various methods of unarmed fight in the late nineteenth and early twentieth centuries. It includes an analysis of the relationship between these methods of struggle and the objectives pursued by establishing various interpretation options of the fights of «suffragists» and "suffragettes». It also aims to make a comparison between suffragette struggle and "passive resistance», beyond the distinction made in the article written by Gandhi about Satyagraha vs. Passive resistance.
\end{abstract}

Keywords: suffragist, means-ends, passive resistance, satyagraha.

\section{O feminismo sufragista: entre a persuasão e a disrupção}

Resumo: O presente artigo apresenta uma revisão das contribuições que o movimento sufragista realizaaos métodos de luta não armada no final do século XIX e início do século XX. Ele faz uma análise da relação entre esses métodos de luta e os objetivos visados, estabelecendo nuances entre as opções de luta entre suffragists y suffragettes. Ele também pretende fazer uma comparação entre a luta sufragista e "resistência passiva",além da distinção feita no artigo escrito por Gandhi sobre Satyagraha vs. "Resistência passiva".

Palavras-chave: sufragismo, meios - fins, resistência passiva, satyagraha. 


\section{Introducción}

En octubre de 2015 se estrenó en el Festival de Cine de Londres, Suffragettes, película que muestra la lucha que llevaron a cabo las mujeres inglesas a finales del siglo XIX y principios del siglo XX por la obtención del voto. La proyección de esta película ha suscitado un renovado interés sobre la historia de las mujeres. Anteriores películas han mostrado múltiples aspectos de este proceso no siempre bien definido entre métodos o medios de lucha y objetivos políticos legítimos en el campo del feminismo. Les résultats du féminisme, la serie de la televisión inglesa, Shoulder to shoulder, Las Bostonianas, Clara Campoamor. La mujer olvidada, ${ }^{1}$ mantienen una relación entre el sufragismo y los medios para obtenerlo.

La producción cinematográfica sobre este tema ha sido más bien exigua. Les résultants du féminisme, (Francia, 1906), Alice Guy. Tiene el mérito de ser la primera obra producida y en plena efervescencia sufragista. Presenta los roles de mujeres y hombres totalmente invertidos y la podríamos calificar como anti-sufragista, pues en la última escena de la cinta, que apenas dura 7 minutos, los hombres irrumpen en el bar y echan fuera a las mujeres a empujones para recobrar el rol que les pertenecía y terminar brindado porque todo vuelva a su sitio. The bostonians, (USA y Gran Bretaña, 1984), James Ivory. Refleja un tipo de lucha sufragista desarrollada en los Estados Unidos que opta por la exposición pública (manifestaciones masivas y alocuciones públicas, etc), por tal motivo resulta clave la sorprendente dote oratoria de su protagonista Verena Tarrant. Ella tendrá que decidir entre el amor de Basil Ramsome, quien encarna ideales totalmente contrarios al feminismo y Olive Chancellor, su tutora, que le brinda una prometedora carrera como portavoz del movimiento ${ }^{2}$. Clara Campoamor. La mujer olvidada (España, 2011), Laura Mañá. Es una película que retrata la conquista del derecho al voto femenino por vías institucionales. Muestra la lucha de la abogada Clara Campoamor, figura representativa del sufragismo femenino español que se salda con el reconocimiento del voto por las Cortes Españolas, el 9 de diciembre de 1931, en una reñida votación.

Shoulder to shoulder ${ }^{3}$ (Gran Bretaña, 1974), idea original de Midge McKenzie et al. Y dirigida por Waris Hussein y Moira Armstrong. Hombro con hombro, fue la primera producción que llevó a la televisión la historia de las mujeres sufragistas inglesas. Es un drama que enfatiza las duras condiciones a las que se enfrentaron las mujeres de finales del siglo XIX y principios del XX y dedica especial atención a los aspectos que corresponden a la campaña más agresiva llevada a cabo por las «suffragettes». Se presenta un movimiento que opta más por acciones directas y coquetea con el sabotaje. Su primer episodio es dedicado a la familia Pankhurst y, entre las escenas que muestra se halla la destrucción de la Venus desnuda en la Galería Nacional y el sacrificio de Emily Davison en el Derby Epson.

Estas representaciones del movimiento sufragista, muestran algunos de los matices que se dieron en su lucha, dónde algunas mujeres opta- 
ron por las vías más institucionales y otras, en cambio, decidieron recurrir, para ser escuchadas, a métodos que tensaron en mayor medida la situación. Esta última situación es la que proyecta la última película, Suffragettes (Reino Unido, 2015), Sarah Gavron. La película hace una clara vinculación entre las obreras inglesas y el movimiento sufragista, al adjudicar el papel protagónico a Maud, (Carey Mulligan), una humilde trabajadora de una fábrica de textiles que resulta involucrada en el movimiento -casi por casualidad- y llega a convertirse en una convencida militante, dispuesta a sacrificarlo todo por la causa sufragista. En el curso de la película también se plasma la radicalización de las mujeres ante la respuesta negativa de acceder a sus reivindicaciones y de cómo cambia la perspectiva de una mujer con la politización que supone integrarse en la lucha sufragista. Las mujeres que participan del movimiento se redescubren y esto tendrá profundos efectos emancipatorios sobre ellas.

En este artículo pretendemos analizar algunos aspectos de esa lucha, no sólo por el voto, sino por mejorar las condiciones objetivas y jurídicas de las mujeres, a través de la elección de unos métodos que rebasaron las vías institucionales y sólo frecuentaron, circunstancial y ocasionalmente, el sabotaje. Las fuentes son amplias pero no tanto cuando se abordan desde esta perspectiva. En nuestro caso, para delimitar aún más este debate medios-fines, señalaremos la relación entre la acción política noviolenta y el sufragismo en un arco temporal más acotado.

Gandhi, uno de los líderes más reputados en la sistematización práctica de los métodos noviolentos sintió mucha curiosidad por la lucha que en Inglaterra estaban adelantando las sufragistas y viajó para reunirse con algunas de sus lideresas. También se conoce un pequeño texto dentro del libro sobre Satyagraha in Southafrica (1925), de 'Satyagraha vs. Resistencia pasiva’ (Lastra 2012: 282-286), en el cual Gandhi presenta su lucha como superadora de la que, según su opinión, realizaban las sufragistas y a la que calificaba -tal y como venían señalando medios políticos- como «resistencia pasiva».

¿Es cierto que la lucha de las mujeres sólo fue de resistencia pasiva? ¿Qué matices podemos identificar entre los métodos usados por los distintos movimientos sufragistas? ¿Se podría hacer paralelismo entre la satyagraha gandhiana y la lucha por el derecho al sufragio más allá de la comparación hecha por el mismo Gandhi en el capítulo ya citado?

Para responder a estas preguntas empezaremos por situar el contexto en el que se desarrolla la lucha sufragista que encierra una órbita más extendida de reivindicaciones por derechos educativos, civiles y políticos. En segundo lugar, nos centraremos en el proceso reivindicativo llevado a cabo por el movimiento sufragista, con especial atención en los métodos de lucha que inauguraron y desarrollaron. Finalmente, compararemos la lucha sufragista con la «resistencia pasiva», aportando algunos elementos a los análisis que ya existen. 


\section{Contexto histórico}

El XIX fue una etapa de profunda codificación social para las mujeres. Las imágenes de la "buena esposa”, "buena madre”, “mujer piadosa”, "reina del hogar", dan muestra de un siglo que se nos presenta hostil para su situación, pues ese genérico "mujer" utilizado por la moral de la época reduce a las féminas a su condición principalmente (y casi únicamente) de madres y, al sometimiento o dependencia de un varón (padre, marido o hermano). También es el siglo del Romanticismo como oposición al Pensamiento Ilustrado. De ahí que la reacción a las vindicaciones de las mujeres sea particularmente ruda y arroje cómo resultado una fuerte prescripción normativa que busca encerrarlas dentro de los límites del amor romántico. Sin embargo, también es el siglo de la expansión del feminismo, movimiento que cambió la perspectiva de la vida de las mujeres y les abrió vías para su acción política y militante.

Aunque con anterioridad el debate sobre si los derechos de las mujeres debían ser los mismos que los de los hombres, si su educación debía estar diferenciada, así como sus actividades y destinos, ya había suscitado el pronunciamiento de reconocidas figuras intelectuales, tanto a favor, (el Marqués de Condorcet, Olympe de Gouges, Mary Wollstonecraft, Charles Fourier, John Stuart Mill, Harriet Taylor, etc.), como en contra, (Jean-Jacques Rousseau, Edmund Burke, Arthur Schopenhauer, Charles Darwin, Friedrich Hegel, Edward H. Clarke, Friedrich Nietzsche, Sigmund Freud, Pablo Moebius, entre otros). Es durante el siglo XIX donde la hegemonía de la moral burguesa relegó, con ímpetu, a «la mujer» al ámbito doméstico y le fijó un estricto código de conducta. Resulta llamativo que algunas de las voces más influyentes del siglo se posicionaran en contra de cualquier entidad de las mujeres como sujetos políticos.

Ese siglo largo que se abre con la Revolución Francesa y se cierra con el inicio de la Gran Guerra, supuso la exclusión de las mujeres del pacto político de la ciudadanía, establecido en la tardo Ilustración. El pensamiento y horizontes que de ella habían emanado -el humanismo, las utopías socialistas, las investigaciones evolucionistas, el cuestionamiento por los orígenes y la historia de la humanidad...-, desplegaron inéditos derroteros y generaron múltiples ilusiones y expectativas. Lo paradójico es que aunque las luchas por la conquista de derechos unieron a hombres y mujeres, éstas quedaron excluidas de esa creación del discurso liberal ilustrado: el «Hombre», ese sujeto generizado y abstracto en el que se fijaron los derechos civiles y políticos y al que se dirigieron los discursos de filósofos, políticos y grandes pensadores. Si eran iguales en la razón, ¿por qué no habrían de tener los mismos derechos? Esta paradoja da lugar al nacimiento del feminismo, «un hijo no querido de la Ilustración», en palabras de Amelia Valcárcel, [yo diría más bien, una hija no querida de la Ilustración]. Esta paradoja no se resolverá en ese siglo e inaugurará un periodo de luchas y reivindicaciones que alcanzarán notoriedad pública. 
Por un lado, las mujeres del siglo XIX, se encontraron entonces entre un discurso moderno emancipador que prometía nuevos y desconocidos horizontes para la humanidad y, por otro, una prédica en la que se honraba, por encima de todo, su papel reproductor y se las incitaba a no salir de la frontera doméstica. Fue también en este siglo donde ganó reconocimiento la oposición entre hogar y trabajo, maternidad y trabajo asalariado y entre feminidad y productividad. Las mujeres de la época dependían casi en su totalidad de un tutor, no podían crear negocios, pedir créditos o realizar cualquier tipo de transacción financiera en nombre propio; se les negaba el reconocimiento profesional de los estudios que adelantaran; hijos e hijas podían ser entregados en adopción por su padre sin pedir la autorización de la madre; no podían quejarse de malos tratos al interior del matrimonio, pues se consideraba «un gaje del oficio»; no tenían derecho al divorcio y mucho menos al aborto. De igual forma, la remuneración del trabajo que desempeñaron era menor que la de sus homólogos varones. Habrá que esperar al siglo XX para que una mujer pueda disponer de su salario. Con todo, el trabajo tendrá una cualidad ambivalente, pues es, a la vez, un lugar de sobreexplotación y de emancipación para ellas.

\section{El sufragismo y sus métodos de lucha}

El sufragismo fue la punta de lanza de un amplio programa reivindicativo de reformas sociales y políticas de las mujeres. Ya era muy evidente a finales del siglo XIX y principios del XX que el incremento de poder, la incursión y conquista de espacios como el trabajo asalariado, el ingreso en los sistemas de educación, la vindicación por la igualdad jurídica y de derechos civiles y políticos, y el reclamo público cada vez más numeroso mostraban la fuerza del movimiento feminista y, en general, el avance y la influencia de las mujeres en numerosos terrenos.

Las consecuencias de la Ilustración se dejaron sentir. En el tránsito de estos siglos, muchas mujeres incursionaron en actividades que hasta ese momento eran desconocidas para ellas. Algunas cultivaron su espíritu y su intelecto a través de los libros y la participación en tertulias, clubes y tribunas. En Francia fueron famosas las llamadas "salonniéres", mujeres que se especializaron en la protección de escritores del Siglo de las Luces. Aquellas que intentaron realizar estudios al mismo nivel que los varones, se encontraron con serias dificultades, como el rechazo al intentar ingresar en la universidad o la ridiculización y la burla de sus compañeros. Hay que recordar que antes de octubre de 1920 las mujeres inglesas no tenían permitido matricularse o graduarse a estos niveles. Desde 1870 algunas mujeres atendían clases, realizaban exámenes y conseguían todos los honores para graduarse, pero su profesionalidad no estaba reconocida pues era privativa de los varones. Para superar estas restricciones las mujeres utilizaron diversas estrategias ${ }^{4}$ : se vistieron de hombre, utilizaron seudónimos para publicar sus escritos, incluso llegaron a presentarse a sí mismas ante los varones como casos excepcionales de «mentes brillantes» para ser aceptadas en circuitos cerrados para ellas como los de las artes, las letras y las ciencias. 
Otras mujeres participaron en organizaciones con ideales de justicia: la lucha por las víctimas de la pobreza, las condiciones insalubres y de explotación y la marginación, el abolicionismo esclavista, la reforma moral, el apoyo a diversas bases teóricas como el socialismo, el anarquismo o el laborismo. Algunas incluso se atrevieron a desarrollar misiones altruistas, como las cuáqueras en sus viajes a Europa para defender la causa antiesclavista. Otras lo hicieron por el simple placer de conocer nuevos mundos. Los lazos internacionalistas y superadores de las fronteras nacionales se estrecharon entre las mujeres. Muchas de clase media buscaron trabajo en las ciudades e inauguraron así una vía de emancipación económica. Salir significó estrenar caminos y sentidos, representó alejarse del espacio doméstico, o mejor, transformarlo en espacio público y, emprender una ruta hacia el protagonismo político y el ejercicio de la futura ciudadanía. Salir y asumir desconocidas tareas y visiones tendría efectos en sus formas de comunicación. Del simple hablar con sus vecinas, familiares y amigas, las mujeres pasaron a desarrollar una compleja red de comunicación y formas variadas de expresión entre las que podemos encontrar: cartas, manuscritos, opúsculos, peticiones, códigos ocultos, etc. Una acción militante y política muy importante que sería desarrollada aún más dentro del movimiento sufragista. Formas todas ellas de micro-resistencia antes o a la espera de pasar a unas formas abiertas de resistencia civil.

Ya en 1848 se había celebrado en Estados Unidos la precursora convención sobre los derechos de las mujeres, un documento al estilo de la «Declaración de Independencia», que reunió a más de 300 personas y dónde más de 100 firmaron y publicaron la llamada "Declaración de Séneca Falls”, en la que denunciaron las restricciones políticas a las que estaban sometidas las mujeres en aquel país. Amelia Valcárcel, traza con maestría una línea entre la Declaración de Sentimientos de Séneca Falls de 1848 y la declaración de Derechos Humanos, liderada por Eleanor Roosevelt, de $1948^{5}$. Así, estos cien años de lucha, evidenciarían, por un lado, el acto fundacional del feminismo sufragista y la última de las grandes luchas de la agenda sufragista. Inicio y final de un camino que recorre un siglo de historia de reivindicación sufragista. Con la Declaración de los Derechos Humanos se considera, finalmente, a la mitad de la humanidad, las mujeres, como sujetos políticos y jurídicos.

La identificación de las mujeres de Estados Unidos con la causa abolicionista fue muy directa. Había, sin duda, muchas similitudes entre la emancipación de las mujeres y la de los esclavos. La Declaración de Seneca Falls fue quizá la máxima expresión de la insatisfacción de las mujeres norteamericanas de cómo estaban siendo tratadas. Sin embargo, terminada la Guerra Civil, las mujeres se hallaron ante una nueva frustración pues se instauró la emancipación de los negros más no la de las mujeres (XV Enmienda de la Constitución, ratificada el 3 de febrero de 1870).

Con la creación de los nuevos estados en el Oeste, se dieron algunos avances en la obtención de derechos políticos y civiles para las mujeres, es de resaltar el caso de Wyoming que en 1869, reconoció el voto a las 
mujeres en iguales condiciones que para los varones. Así también los nuevos estados siguen la tendencia de aprobar el sufragio femenino para las elecciones locales. Tales como: Utah (1870), Colorado (1893), Idaho (1896), Washington (1910), California (1911), Oregón, Arizona y Kansas (1912) y Nevada y Montana (1914).

En el caso norteamericano es destacable el trabajo de dos organizaciones que a raíz de la ratificación de la XV Enmienda se vieron enfrentadas. Por un lado, la “American Woman Suffrage Association” (AWSA, Asociación Americana por el Sufragio Femenino), creada en 1869 y que tuvo como fundadores a Lucy Stone, Henry Blackwell y Julia Ward, abolicionistas convencidos que creían que incluir el voto para las mujeres pondría en peligro la aprobación de la Enmienda que aseguraba el voto para los hombres afroamericanos. Por otro lado, la "Nationa Woman Suffrage Association” (NWSA, Asociación Nacional de Mujeres Sufragistas), también nacida en 1869 en la ciudad de Nueva York por Susan B. Anthony y Elizabeth Cady Stanton, de postura contraria a la XV Enmienda Constitucional a menos que incluyera el voto para las mujeres. Estas dos organizaciones se dieron cuenta en 1890 que el periodo que siguió a la culminación de la Guerra Civil no había dado los frutos deseados para avanzar en la obtención de derechos de las mujeres. A partir de esa convicción decidieron fusionarse y aunar esfuerzos para presionar de manera más efectiva al gobierno y es así como forman la "National American Woman Suffrage Association” (NAWSA, Asociación Nacional Americana de Mujeres Sufragistas).

Esta última organización llevó a cabo una estrategia que consistía en mantener el entusiasmo de sus afiliadas por medio de la realización de convenciones anuales y, a su vez, llamar la atención de la opinión pública a través de la ejecución de grandes y teatrales desfiles pro sufragio, y la publicación de toda suerte de folletos, periódicos, libros y una prensa comprometida con la causa. El caminar de estas organizaciones abre un periodo de presión y crecimiento del movimiento que presenta y lucha por su programa reivindicativo. Aunque en el proceso se consiguen algunas mejoras en la situación de las mujeres, como las referidas a empleo y sueldo o el acceso más fácil al divorcio, habrá que esperar hasta 1920 cuando mediante la aprobación de la XIX Enmienda de la Constitución se reconozca el derecho de las mujeres a votar en los Estados Unidos. En Francia, en 1851 Pierre Leroux ${ }^{6}$ presentó el primer proyecto de ley parlamentaria para reconocer a las mujeres el derecho al voto en las elecciones municipales, pero no tuvo éxito. Es irónico que las mujeres participaran masivamente en las revoluciones de 1848, y no sólo en Francia, instalando barricadas, haciendo parte de los sindicatos, participando de las huelgas por mejores condiciones en lavanderías o fábricas textiles y, sin embargo, sus reivindicaciones se vean postergadas. La cuestión del sufragio no hizo parte de la discusión pública hasta la década de 1870 con el establecimiento de la Tercera República. Un hecho, que se suele relatar como anecdótico da cuenta del cariz de la situación de discriminación a la que eran sometidas las mujeres usando a conveniencia el lenguaje. Mme. Barbarousse reclamó el derecho de voto para 
todas las personas -hombres y mujeres- argumentando que las leyes básicas de la República reconocían el derecho al voto a todos los franceses; pero en 1885 los tribunales decidieron que cuando las leyes se referían a «franceses» lo hacían en sentido literal, es decir, solamente todos los varones adultos podían votar, pero no las mujeres.

En este contexto histórico nacieron diversas organizaciones sufragistas en Francia como la "Societé le Droit des Femmes”, (Asociación para los Derechos de las Mujeres), fundada en 1876 por la reconocida dirigente del movimiento feminista francés, Hubertine Auclert. Su activismo incluía además de la revisión del Código Napoleónico, reivindicaciones en términos de educación, acceso a los colegios profesionales, independencia económica, reconocimiento de derechos de la mujer casada que era considerada inferior al hombre o a la libre maternidad, entre otros. En 1880, y ante las negativas del movimiento obrero a incluir las reivindicaciones de las mujeres, Auclert hizo un llamamiento a la insumisión y la no cooperación con las leyes. Según argumentaba, si las mujeres no eran sujetos jurídicos, entonces se debían oponer al pago de impuestos, pues no existían para la institucionalidad. Además, se la conoce por su lucha por la legalización del divorcio, aprobado en 1884 por el gobierno francés, y por la petición de un contrato matrimonial con separación de bienes. Junto con Marguerite Durand, otra figura de la lucha feminista francesa, crean publicaciones periódicas que mantienen en la agenda pública las reivindicaciones de las mujeres, como, “La Citoyenne” y “La Fronde”. Otra organización sufragista francesa que se hizo muy visible fue la Union française pour le suffrage de femmes (UFSF). El 5 de julio de 1914, antes del estallido de la Gran Guerra, mostraban su fuerza en una masiva manifestación en honor de Condorcet ${ }^{\text {, }}$, saliendo a la calle con sus 9.000 afiliadas (Thébaud1993: 49). Son apenas algunas de las muestras de la que ha sido considerada como la época de oro del sufragismo francés que, sin embargo, tuvo que esperar largo tiempo para ver realizadas sus demandas. Las francesas no obtuvieron el derecho al voto hasta 1945, prácticamente un siglo después de habérsele reconocido este mismo derecho a los hombres, en 1848.

En Gran Bretaña la lucha sufragista en el ámbito público había sido inaugurada por el filósofo y parlamentario, John Stuart Mill, cuando presentó en 1867 una Enmienda para reconocer el voto a las mujeres. La Enmienda no tuvo los apoyos suficientes. Tras su derrota, Mill publicará una de las obras célebres del feminismo, “The Subjection of Women”, 8 un alegato muy sistemático contra la sociedad patriarcal tradicional, que abogaba por la incorporación de las mujeres a la sociedad civil en pie de igualdad con los varones.

En el caso inglés resulta vital el aporte de dos organizaciones que se han descrito como antagónicas, obviando, en ocasiones, las muchas sinergias y solidaridad que se dio entre ellas (Palomo Cermeño 2015: 84). La “National Union of Women's Suffrage Societies”, (NUWSS, Unión Nacional de Sociedades de Mujeres Sufragistas), conocidas también como “suffragists”. Fundada en 1887 y cuyas cabezas más visibles fueron Millicent 
Garrett Fawcett y Lydia Becker, fue una organización que agrupaba a 480 sociedades pro-sufragio y contaba con más de 53.000 afiliadas (Thébaud1993: 50). Compuesta por mujeres de clase media y obreras y con la participación de algunos hombres, desarrolló acciones centradas en la persuasión de los parlamentarios de la necesidad de aprobar el derecho al voto de las mujeres. Sus tácticas fueron pacíficas, constitucionales y siempre comedidas y respetuosas. Esta organización puso en marcha todas las formas recogidas en el apartado de declaraciones formales de los métodos de concienciación, persuasión y protesta noviolenta de Gene Sharp (López Martínez 2006: 332). En su haber tienen gran cantidad de discursos públicos, cartas de petición de apoyo a cada uno de los parlamentarios de tanto en la Cámara de los Comunes como de los Lores, declaraciones públicas y firmas masivas de declaraciones y peticiones para la aprobación del sufragio femenino dirigidas al Parlamento inglés, etc.

La primera procesión organizada por la NUWSS fue la que se conocería como la «Mud March» (Marcha del Barro o Marcha del Lodo), celebrada en febrero de 1907 y que pasaría a la historia como una de las caminatas más simbólicas llevadas a cabo por el movimiento sufragista inglés. Más de 3.000 mujeres marcharon desde Hyde Park a Exeter Hall para abogar por el sufragio femenino. Se habían unido distintas delegaciones procedentes de diversas ciudades del Estado. Esta demostración de fuerza tuvo un impacto considerabledebido a la novedaddel espectáculo, resultaba sorprendente ver a mujeresrespetablesmarchando por las calles.Smith 2013: 23) Acciones como esta dieron cuenta de que las militantes sufragistas arriesgaron, en muchas ocasiones, susreputaciones y su empleo, además de someterse al ridículo con su exposición pública. Las acciones de este tipo, por supuesto, se multiplicarían en el curso de la lucha sufragista. ${ }^{9}$

También en Gran Bretaña la Women's Social and Political Union (WSPU), organización que se había escindido de la NUWSS, establecida en 1903, bajo el liderazgo de EmmelinePankhurst y cuyas afiliadas fueron conocidas también como “militant women", "suffragettes” o, en sentido peyorativo, como "las furias criminales de Londres” debido a su decisión de utilizar métodos más impactantes de acción directa para que fueran oídas y asumidas sus reivindicaciones, logró situar el debate del sufragio femenino en primer plano. (Thébaud1993: 49) Incluso se puede demostrar la mucha influencia que tuvieron en la generación de conciencia a favor de los derechos de las mujeres. Algunas de sus militants también tuvieron participación en grupos como: “The Women's Freedom League”, “The Men's Political Union”, "The Women's Tax Resistance League”, "The East London Federation of Suffragettes”, etc. (Smith 2013: 34)

Las mujeres de principios de siglo crearon una compleja red comunicativa y organizacional. En 1907, bajo la presidencia de Clara Zetkin, se reunió la I Conferencia Internacional de Mujeres Socialistas en Stuttgart (Alemania), a la que asistieron 58 participantes de Europa, India y Japón que adoptaron una resolución sobre el derecho del voto femenino como el punto de partida de una lucha incesante por los derechos políticos de las 
mujeres. En una conferencia posterior, en 1910, se aprobaría la resolución que señalaba una jornada al año como Día Internacional de la Mujer y que proponía aprovecharlo para hacer campaña por el derecho de las mujeres al voto y por su emancipación política. Esta misma organización adoptó una resolución sobre la paz y, en 1912, celebró una conferencia extraordinaria, para observar la situación con respecto a la paz y comprometerse para poner fin a la guerra de los Balcanes.

El sufragismo fue clave pues logró politizar y desmoronar la imagen de un "sexo débil”, pasional y subordinado. En muchas ocasiones sus métodos, sorprendentes e imaginativos de “acción directa”, modernizaron el elenco de formas de protesta, consiguiendo con sus acciones remover los más profundos símbolos y elementos de la cultura hegemónica. Mujeres de clase media, cultas y bien vestidas tensionando las «buenas costumbres» y normas sociales del orden público. Las “suffragettes” británicas son recordadas por haber sido en múltiples oportunidades encarceladas, realizar huelgas de hambre, (a las que, incluso se las alimentó contra su voluntad), interrumpir discursos de ministros, acometer pequeños actos de sabotaje como, romper cristales de edificios oficiales, incendiar comercios o destrozar escaparates, insultar a políticos y policías, atacar los domicilios de destacados miembros del parlamento, como el Primer Ministro Asquith ${ }^{10}$ y realizar pequeños atentados contra la propiedad, sin nunca llegar a lastimar a personas; simular votaciones en colegios electorales, encadenarse en lugares públicos, etc. Por su carga dramática y su lectura política es recordado el episodio que condujo a la muerte a Emily WildingDavison, una de las activistas fundadoras del WSPU, cuando intentó colgar un cartel sufragista en el caballo propiedad del rey Jorge $\mathrm{V}$, que participaba en el Derby Epsom. De este episodio trágico se cumplieron cien años el pasado 4 de junio de 2013. Todos estos hechos confirman que los reclamos de la mitad de la humanidad resultaban incómodos y difíciles de acallar por el patriarcado contemporáneo. “1914 habría podido ser el año de las mujeres. [Sin embargo,] es el año de la guerra, el que vuelve a poner a cada sexo en su sitio” (Thébaud1993: 50).

La paradoja fue que la Gran Guerra consiguió desactivar el Movimiento Sufragista, corriente que había sido el motor de la toma de conciencia sobre el reclamo de una ciudadanía para las mujeres, así como impulsor también de un asociacionismo de solidaridad para la lucha conjunta por los derechos de las mujeres. La contienda mundial significó además, una división en el seno mismo del feminismo entre las mujeres que pusieron sus organizaciones al servicio del nacionalismo, el sentimiento patriótico y la conscripción militar y aquellas que tomaron la opción del pacifismo y lucharon para evitar la guerra.

La prueba de esto, en Gran Bretaña, fue que las dos organizaciones sufragistas más fuertes se dividieron y, tanto la parte más beligerante, la WSPU, como la más moderada, la NUWSS, suspendieron sus campañas reivindicativas a favor de los derechos de las mujeres. Tanto unas como otras se dedicaron a apoyar los esfuerzos de la guerra. Las primeras fueron 
partidarias de la participación de las mujeres en la ofensiva en las mismas condiciones que los varones. Por esta razón crearon comités de reclutamiento en los que pedían a las mujeres animar a sus maridos a luchar o regalar plumas blancas a los hombres que no se habían ido a la refriega ${ }^{11}$, también apoyaron la fabricación de material bélico por parte de las mujeres. Las segundas, calcularon que el esfuerzo de guerra beneficiaría al movimiento sufragista y defendieron una participación de las mujeres con un mayor sesgo de género, invitándolas a alistarse en el llamado "Ejército Voluntario de Mujeres”, éstas luego trabajarían como enfermeras en el «Destacamento de Ayuda Voluntaria» (VAD, por sus siglas en inglés), reforzando así el papel de cuidadoras otorgado a las féminas.

Entretanto, esta decisión suscitó división entre sus afiliadas. Quizá el caso más conocido fue el de Sylvia Pankhurst (hija de Emmeline Pankhurst), quien se distanció de su madre y hermana (Christabel) y prefirió crear una nueva organización, la Workers' Suffrage Federation que se opuso a la IGM, además de denunciar la doble victimización de las mujeres en tiempos de guerra. Con su firme acción pacifista se dedicó a establecer alianzas con el anarquismo, el comunismo, el antiimperialismo y el anticolonialismo y buscar salidas a la sinrazón que estaba siendo la contienda. La opción del pacifismo también fue la elegida por Charlotte Despard ${ }^{12}$, una de las sufragistas que se reuniría con Gandhi en la primera década del siglo XX y a la que se le atribuye la práctica de la que era llamada "resistencia pasiva”.

El feminismo sufragista no se repondría hasta bien terminada la guerra, retomando su clásica agenda política (derecho a la educación, capacitación profesional e igualdad jurídica), pero el daño psicológico y moral de la guerra no dejaría indolentes a muchas de sus pioneras. El feminismo, en cierta medida, se fragmentó de cara al inmediato futuro y no volvería a ser un solo bloque nunca más.

\section{El sufragismo y Gandhi. “Resistencia pasiva” y Satyagraha}

Gandhi expresó públicamente curiosidad y atracción por el movimiento sufragista inglés. En una de sus visitas está documentada esa simpatía, en el artículo que realizó para “Indian Opinion”, titulado “Deeds Better Than Words”, -Hechos mejor que palabras-, (Gandhi, 1906). En su escrito describía un episodio que él mismo había presenciado, en el que fueron arrestadas cerca de 20 mujeres por acosar a los miembros de la Cámara de los Comunes y causar algunos daños materiales. Mencionaba los diversos medios por los que las mujeres expresaban sus reivindicaciones (peticiones, cartas, discursos, etc.) haciendo especial mención a que fueron condenadas a prisión al negarse a pagar la multa que se les impuso. A Gandhi le sorprendió que las mujeres condenadas proviniesen de respetables familias y expresó, particularmente, su admiración por las palabras pronunciadas por una de ellas ante el juez. La mujer declaró que nunca más obedecería unas leyes que habían sido construidas sin contar con su participación y que estaba dispuesta a que la enviasen a la cárcel, -ante lo que 
no opondría resistencia alguna- y, finalmente, sostenía que en ningún caso pagaría la multa. Gandhi reflexionaba en su escrito sobre la valentía y el arrojo de las mujeres e incitaba a los indios del Transvaal a seguir su ejemplo y perder el miedo a los castigos que se podrían desprender de una desobediencia civil, les transmitía que las palabras tenían fuerza, sí, pero que más fuerza tenían los hechos, los hechos eran mejores que las palabras. (Hunt 2005: 96-97)

A partir de las reflexiones de Gandhi sobre la lucha de las mujeres por el derecho al voto encontramos varios paralelismos con la lucha de los indios del Transvaal, ambos se trataban de un reconocimiento de un derecho y no de un mero privilegio, lo cual les dotaba de legitimidad y daba sentido a su sacrificio; las mujeres habían utilizado por largo tiempo unos medios moderados sin haber sido tenidas en cuenta, así como él adelantaba su trabajo en Sudáfrica desde 1892, sin apenas conseguir mejoras en la condición de los indios; las mujeres habían decidido pasar al uso de métodos de acción directa y de desobediencia civil abierta, negándose a pagar impuestos y dejándose llevar a prisión, con lo cual cumplían parte del programa que Gandhi había pensado para los indios; por último, aunque las mujeres al igual que los indios no habían obtenido sus reivindicaciones, Gandhi estaba seguro de que, al final, lo harían, pues la "fuerza de la verdad” triunfaría. (Hunt 2005: 97-98)

Así, en los meses posteriores, Gandhi usaría el ejemplo de la lucha sufragista para animar a sus seguidores y varios artículos aparecerían en “Indian Opinion”, el 29 de junio y el diciembre 28 de diciembre de 1907 y el 11 de abril de 1908 (Hunt 2005: 101). En 1909 Gandhi viajó, de nuevo, a Inglaterra y se reunió con Charlotte Despard, personaje que encarnaba los atributos de valentía y sacrificio que él tanto admiraba en las mujeres británicas. Con ella tenía, además, varios puntos en común, como la práctica del vegetarianismo o las reflexiones en torno a la "fuerza moral” ó "fuerza espiritual”. También conoció, personalmente a Emmeline Pethick-Lawrence y a Emmeline Pankhurst, dos de las dirigentes del movimiento sufragista.

Ahora bien, si ambas luchas tenían, al parecer tales similitudes, ¿Por qué Gandhi prefiere hacer una diferenciación entre la lucha de las mujeres y la lucha de los indios? ¿Por qué le denomina «resistencia pasiva» a la lucha que libran las mujeres por el voto? y ¿Cuáles son las diferencias fundamentales según el texto de Gandhi entre Satyagraha y “resistencia pasiva”?

Parece ser que Gandhi quiso hacer esta diferenciación para obtener el beneplácito de ciertos sectores que no veían con buenos ojos las reivindicaciones de las mujeres, de esta forma podría explicarse que respondiera al señor Hosken, (uno de los magnates de Johannesburgo, como Gandhi mismo lo reconoce), quien había observado que "Los indios del Transvaal han recurrido a la resistencia pasiva cuando otros medios para conseguir el desagravio han resultado inútiles. No disfrutan del derecho al voto. Son solo unos pocos en número. Son débiles y no tienen armas. Por esto han escogido la resistencia pasiva, que es un arma propia del débil”' (Lastra 2012: 282) 
Al verse interpelado por sorpresa por esta observación, Gandhi alteró el discurso que tenía preparado y expuso que la "resistencia pasiva" llevada a cabo por los indios era, en realidad, "fuerza del alma". No podemos perder de vista el contexto colonial que enmarca su lucha, para la cual se hacía necesario recabar apoyos y acudir a fuentes de financiación. "Me di cuenta en esta conferencia de que el uso del concepto «resistencia pasiva» podía dar lugar a una confusión indeseable” (Lastra 2012: 283). Parece legítimo pensar que Gandhi quiso darle una entidad propia a su lucha y diferenciarla de aquellas que representaran una pérdida de prestigio ante la opinión pública.

En el siguiente cuadro se sintetizan las cualidades que Gandhi atribuyó tanto a la «resistencia pasiva» como a la "Fuerza del Alma” ó, Satyagraha.

\begin{tabular}{|l|l|}
\hline \multicolumn{1}{|c|}{ Resistencia pasiva } & \multicolumn{1}{c|}{ "Satyagraha" ó Fuerza del alma } \\
\hline $\begin{array}{l}\text { Para grupos sin derecho al voto, minorías, } \\
\text { débiles y que no tienen armas }\end{array}$ & No siempre y en todos los casos \\
\hline Lugar para el odio & Lugar para el amor \\
\hline $\begin{array}{l}\text { No se puede ofrecer a los cercanos porque los } \\
\text { distanciaría de nosotros }\end{array}$ & Se ofrece a los más cercanos y estimados \\
\hline $\begin{array}{l}\text { Siempre está presente la intención de hostigar } \\
\text { al otro bando }\end{array}$ & $\begin{array}{l}\text { No existe la más remota intención de dañar al } \\
\text { otro bando }\end{array}$ \\
\hline $\begin{array}{l}\text { Deja abierta la posibilidad del uso de las } \\
\text { armas cuando se presente la situación } \\
\text { adecuada }\end{array}$ & $\begin{array}{l}\text { Está prohibida esta posibilidad incluso aunque } \\
\text { las circunstancias sean propicias para ello }\end{array}$ \\
\hline $\begin{array}{l}\text { Se está dispuesto a sufrir cualquier penalidad } \\
\text { que nos resulte de esta actividad }\end{array}$ & $\begin{array}{l}\text { Postula la conquista del adversario mediante } \\
\text { el sufrimiento propio }\end{array}$ \\
\hline $\begin{array}{l}\text { Puede ser una preparación para el uso de la } \\
\text { fuerza }\end{array}$ & $\begin{array}{l}\text { No se admitiría jamás tal uso } \\
\text { uso de las armas }\end{array}$ \\
\hline
\end{tabular}

Fuente: M. Gandhi: “Satyagraha vs. Resistencia pasiva”, en Lastra, A. (2012) Desobediencia civil. Historia y antología de un concepto.

Tecnos, Madrid, pp. 282-286. Elaboración propia.

Si nos fijamos, existen, al menos, tres condiciones consustanciales a la Satyagraha, que la diferencian de la "resistencia pasiva”, es un arma de 
los fuertes, no admite violencia alguna bajo ninguna circunstancia y siempre insiste en la verdad. Habría que sumar otra condición que las distancia, debe practicar una gradualidad en la utilización de los medios de lucha y usarlos, básicamente, para la conversión del adversario.

La diferenciación que hace Gandhi, parece remitir a la deriva de la radicalización de la lucha de las mujeres británicas después de 1909 cuando la WSPU se escinde y algunas de sus reconocidas lideresas emprenden nuevos derroteros al frente de otras organizaciones (recuérdese los casos de Emmeline thick-Lawrence, Charlotte Despard y Sylvia Pankhurst). Ese año marca, precisamente, el inicio de acciones calificadas por la crítica de la época como «violentas» bajo el liderazgo de EmmelinePankhurst y su hija Christabel.

A juzgar por el relato que se ha hecho del sufragismo, ninguno de los matices de su lucha, ni el de las llamadas "suffragist" ni el de las denominadas "suffragettes" parece ajustarse a la descripción de "resistencia pasiva" elaborada por Gandhi. Unas y otras se alejan de la definición de “pasiva”. Desde el principio rompen moldes y actúan de manera activa para conseguir un fin que encuentran legítimo y que brinda la posibilidad del ejercicio real de la ciudadanía no como meras receptoras de las leyes, sino como protagonistas en la construcción de las normas que deben orientar a la sociedad.

En uno de los discursos pronunciados por Emmeline Pankhurst, en el Royal Albert Hall de Londres, el 17 de octubre de 1912, y considerado por la crítica como uno de los más “incendiarios” y “de incitación a la violencia” parece claro que los enemigos de las mujeres no son los hombres sino la negativa de los mismos a reconocer sus legítimos derechos. Se queja Pankhurst de que los derechos de la «propiedad» se consideren "sagrados” y a las personas, a ellas mismas, se las trate de una forma tan vejatoria, (alimentación forzada, reclusión en las zonas de la cárcel destinadas a criminales, cargas policiales cada vez más rudas, puesta en marcha de la conocida como “Cat and Mouse Act” -Ley del Gato y el Ratón, etc.). En esta alocución, Pankhurst insta a las mujeres a llevar a cabo su lucha de la forma que cada una considere, apela a la libertad y a la creatividad de sus seguidoras: "Aquellas de vosotras que puedan expresar la militancia yendo a la Cámara de los Comunes y rehusando salir [... A Aquellas que puedan romper ventanas. Aquellas que puedan atacar el secreto ídolo de la propiedad a fin de que el Gobierno se dé cuenta de que la propiedad está en peligro por las mujeres sufragistas, como lo estuvo en el pasado por los Cartistas, hacedlo. Y mis últimas palabras son para el Gobierno: ¡Yo incito en esta reunión a la rebelión! [...] (Schneir: 295, traducción propia). Esta escena es recogida en la película Suffragettes.

Sin embargo, si continuáramos explorando para hallar similitudes nos encontraríamos con varias coincidencias entre la formación de las mujeres como militantes ó soldados de la causa sufragista y la formación y puesta en escena de lo que Gandhi denominaría el ejército de Satyagrahis. 
Tenemos varias razones para pensar que las sufragistas formaban un "ejército": las marchas, procesiones y exhibiciones públicas del movimiento se planean con sumo cuidado, las ropas que lucen, la uniformidad de sus desfiles e incluso el entrenamiento al que se someten son algunas de las pistas para aseverarlo. "Una de las más famosas manifestaciones fue la celebrada el 21 de junio de 1908 en Hyde Park. La prensa dio cifras que oscilaban entre las trescientas mil y el medio millón de personas, en su mayoría mujeres. El trabajo de propaganda realizado para preparar esta acción fue intenso. Las militantes recorrieron los barrios casa por casa, repartieron propaganda en todos los lugares públicos e incluso alquilaron un barco que navegó por el Támesis hasta el Parlamento. La marcha se organizó como una procesión militar en la que miles de mujeres vestían con los mismos colores simbólicos de la WSPU, blanco (pureza), verde (esperanza) y morado (dignidad), portando banderas y pancartas [...]" (Palomo Cermeño 2015: 101)

Aún más, algunas de las estrategias asumidas por las mujeres denota fines y puesta en escena muy análogos a la lucha desarrollada por Gandhi en la India. A finales de 1913 se fusionaron dos estrategias del movimiento sufragista, por un lado, el llamado "People’sArmy", (ejército del pueblo), organización mixta preparada para afrontar la brutalidad de la violencia policial en las manifestaciones y otros actos públicos. Por otro lado, la iniciativa conocida como la "Rent strike", (huelga de los alquileres), que consistía en no pagar el alquiler en señal de protesta y hacía parte de la campaña "Sin voto no pagamos el alquiler". "En el invierno de 1913, setecientas mujeres formaban parte del People's Army, lo que llegó a preocupar seriamente a Scotland Yard” (Ibid: 121)

Se tiende a atribuir a Gandhi la iniciación de fórmulas de lucha no armada, "Gandhi construyó por primera vez, con la experiencia sudafricana que posteriormente trasladó a la India, valerosos soldados sin armas, satyagrahis, que no tenían miedo de acabar en lúgubres prisiones, picando piedras o, incluso, muriendo por la dignidad de la comunidad india. De ser miserables inmigrados, harapientos sin esperanza, campesinos empobrecidos y mujeres en condiciones de semi-esclavitud, pasaron a ocupar las portadas de los más importantes rotativos de la prensa occidental [...]" (López Martínez 2012: 62). Nadie duda de la originalidad y particularidad de la lucha no armada, o mejor, noviolenta que Gandhi lega a la humanidad, sin embargo, haría falta ahondar más en los posibles nexos que, seguramente, existieron entre la lucha sufragista y la lucha gandhiana, pues la primera sirve, así como la lucha obrera, de referente a las acciones que Gandhi iría perfeccionando en su Satyagraha.

Algunos autores y autoras, sin embargo, deducen que fue en el seno del movimiento sufragista donde se crean las estrategias de desobediencia civil en sentido moderno. (Castañar 2013: 116), asimismo, hay quien afirma que se debe al sufragismo la aportación de los métodos de lucha cívica actual que resultan tan comunes entre los movimientos sociales contemporáneos, (Valcárcel 2009: 89) 


\section{Conclusiones}

Como bien se ha podido observar en el breve recorrido cinematográfico referido a la lucha sufragista, las producciones parecen pocas si consideramos las profundas consecuencias que tuvo no sólo para la vida de las mujeres, sino también para el cambio social y la generación y puesta en marcha de acciones de persuasión, concientización y protesta y las de acción directa para el movimiento sufragista en el mundo.

No debemos perder de vista que el siglo XIX está marcado por la irrupción de las masas en la historia y que resulta paradójico que en aquellos países que se autoproclamaban como los más respetuosos de los derechos y las libertades (USA, Gran Bretaña, Francia, Canadá, entre otros muchos), sean los que oponen fortísimas resistencias a las reivindicaciones de las mujeres.

Es de anotar que la falta de reconocimiento del aporte de la lucha sufragista de las mujeres a las formas de resistencia, desobediencia civil y noviolencia, quizá sea producto de la inercia de la sociedad patriarcal que tiende a invisibilizar y a subvalorar a las mujeres.

Del catálogo de 198 métodos y técnicas de acción noviolenta de Sharp, las sufragistas utilizaron un amplio abanico. No sería equivocado afirmar que los métodos usados, quizá sin buscarlo, nos muestran una cierta gradualidad. Es decir, de métodos de persuasión, concientización y protesta, se pasa luego a usar fórmulas de no cooperación y no colaboración, para terminar recurriendo a formas más contundentes de acción directa. Sin embargo, aun estando claro el objetivo del sufragismo, lo que divide al movimiento en su interior son los métodos utilizados para lograrlo. Para algunas de sus militantes, se deben agotar primero todas las vías institucionales, (son las llamadas suffragists) con posiciones más cercanas a lo propuesto por Gandhi en su Satyagraha. Del conjunto de métodos citados, éstas militantes tuvieron serios problemas e incluso se negaron absolutamente a la utilización de métodos de acción directa (aunque esta fuera noviolenta); sin embargo, las que pasarían a la historia con el nombre de suffragettes, no sólo utilizaron todo el repertorio de métodos indicados, sino que su proceso de radicalización les condujo al uso de formas más disruptivas de acción directa.

La obtención del sufragio no es, sin embargo, un fin en sí mismo, sino la apertura a la emancipación de las mujeres. Se trataba de pasar de ser simples receptoras de leyes a protagonizar su construcción. Asimismo, las mejoras que se producen a lo largo de la lucha, en otros campos, condición de las mujeres casadas, prerrogativas laborales, divorcio, etc., no dejan de ser concesiones que los sistemas hacen, en algunos casos, para acallar la protesta, pero se siguen resistiendo a reconocer una entidad política completa a las mujeres.

En la comparación de Satyagraha vs. "Resistencia Pasiva”, queda 
medianamente claro que el aporte de Gandhi en este documento es algo coyuntural y precipitado, aunque luego se entienda mejor, cuando algunas vías del movimiento sufragista se inclinen más por la radicalización. Lo que se podría interpretar como una consecuencia de la gran resistencia patriarcal a reconocer el voto a las mujeres. 


\section{Notas}

${ }^{1}$ http://sheyehs.blogspot.com.es/p/peliculas-feministas.html [Consulta: 18-01-2016]

${ }^{2}$ En la novela original en la que se basa la película, su autor, Henry James, acude al tan usado recurso de la época de relacionar sufragismo e histerismo, otorgando a la sufragista, Olive, características propias de este «mal»: nerviosismo, miedo irracional, ansiedad y ataques de timidez. (Millares 2005: 253)

${ }^{3}$ Es posible que el título de la serie se inspirara en las palabras pronunciadas en 1906 por la una de las sufragistas más reconocidas de la Women's Social and Political Union (WSPU), Emmeline Pethick-Lawrence y publicadas en el Labour Record: "No puede haber vuelta atrás... Nuestro único referente somos nosotras mismas. Sólo contamos con las mujeres para levantarnos hombro con hombro... mujeres que saben lo que les espera y que no tienen miedo" (Palomo Cermeño 2015: 91-92). Estás palabras, sin duda, reflejan el tono de entusiasmo y compromiso de las mujeres con la causa sufragista.

${ }^{4}$ Son conocidos los casos de las hermanas Brontë que para evitar los prejuicios que sobre las mujeres existían en su época, -la sociedad victoriana-, adoptaron nombres masculinos y de esta forma publicaron sus obras.

${ }^{5}$ Ver: https://www.youtube.com/watch?v=Yell2AbX0zI [En línea] Apartes de la conferencia impartida por Amelia Valcárcel en el marco de la Cátedra Alfonso Reyes, en México. [consulta: 31-05-2014].

${ }^{6}$ Pierre Leroux (Bercy, 1797- París, 1871), fue un filósofo y político socialista. Uno de los redactores de la Encyclopédienouvelle (1836-1843), obra fundamental del socialismo y republicanismo del siglo XIX. Ver: http://www.biografiasyvidas.com/biografia/ l/leroux.htm

${ }^{7}$ Marie-Jean-Antoine Nicolas de Caritat, Marqués de Condorcet (Ribemont, 1743 Bourg-la-Reine, 1794), fue un científico, filósofo y político francés. Su vinculación con el movimiento feminista se remonta a su defensa de los derechos de las mujeres, pedía para ellas, por ejemplo, la ciudadanía y una educación igualitaria para ambos sexos, (Puleo 1993: 96).

${ }^{8}$ John Stuart Mill (Londres, 1806 - Aviñón, Francia, 1873), fue un filósofo, político y economista inglés de origen escocés. Calificado en su época como radical por su defensa de la educación obligatoria, la igualdad de las mujeres y el control de la natalidad, entre otros. Es conocido por obras como: «Un sistema de lógica, 1843», «Ensayos sobre algunas cuestiones disputadas en economía política, 1844, «Sobre la libertad, 1859», «, », etc. Junto a su esposa, Harriet Taylor, desarrolló su pensamiento más feminista y publicó su famosa obra, «The Subjection of Women, 1869» (El sometimiento de las mujeres).

${ }^{9}$ http://spartacus-educational.com/Wpilgimage.htm [consulta: 19-01-2016].

${ }^{10}$ Herbert Henry Asquith(Morely, Yorkshire, 1852 - Londres, 1928), fue un abogado y político liberal británico. Elegido diputado desde 1886, también se desempeño los cargos de Ministro del Interior (1892 - 1895) y Ministro de Hacienda (1905 -1908). Se convirtió en Primer Ministro del Reino Unido (1908 a 1916), tras la renuncia de 
Campbell-Bannerman. Fue conocido como un antisufragista acérrimo por lo que se convirtió en blanco de las presiones de las sufragistas. Los ventanales de su casa en Downing Street fueron rotos en varias ocasiones y, en otras, militantes del movimiento se encadenaron a sus verjas. (Palomo Cermeño 2015: 102). Durante el mandato de Asquith el gobierno intensificó su represión tanto en las calles como en las cárceles. Se instauraron prácticas como la criticada alimentación forzada, el confinamiento en celdas de castigo o el aislamiento a las reclusas. (Ibid: 103-104)

${ }^{11}$ Las plumas blancas empezaron a usarse como regalo que las mujeres daban a los hombres para avergonzarlos por no ir al combate durante la Primera Guerra Mundial. A este movimiento se unieron, por ejemplo, sufragistas como Emmeline Pankhurst y su hija Christabel.

${ }^{12}$ Charlotte Despard (Edinburgo, 1844 - Dublín, 1939) polifacética pacifista, socialista y sufragista irlandesa, criada en Inglaterra. Perteneció tanto a la NUWSS como a la WSPU. En 1907 y como consecuencia de sus desavenencias con Emmeline Pankhurst, por el distanciamiento entre la WSPU y el Laborismo, se retiró de la organización y, junto a otras mujeres, fundó la Women's Freedom League (WFL), de cuya labor se creó, también, el diario «The Vote», publicado desde 1909 hasta 1933. (Smith 2013: xviii). Despard apoyó diversas causas: fue activista del Sinn Fein, militante republicana, practicó el vegetarianismo y acompañó diversas campañas anti-fascistas y a favor de la paz mundial. Por esta última simpatía fue fundadora de la «Women International League for Peace and Freedom» (WILPF, Liga Internacional de Mujeres por la Paz y la Libertad) una de las organizaciones feminista y pacifista más antigua e importante del mundo. Despard también lideró campañas de desobediencia civil como la de negarse a pagar impuestos, «Tax Resistance League» y boicotear el Censo de 1911, negándose, junto a muchas otra mujeres, a proporcionar información. Dedicó toda su vida a trabajar por causas sociales. 
Polis, Revista Latinoamericana, Volumen 15, $N^{\circ}$ 43, 2016

\section{Bibliografía}

Amorós, Celia (1997),Tiempo de feminismo. Sobre feminismo, proyecto ilustrado y postmodernidad. Cátedra, Madrid.

Castañar Pérez, Jesús (2013), Teoría e historia de la revolución noviolenta. Virus editorial, Bilbao.

Gandhi, Mohandas Karamchand (1926), "Satyagraha vs. Resistencia pasiva” En: Lastra, Antonio ed. (2012), Desobediencia Civil. Historia y antología de un concepto. Tecnos, Madrid, pp. 282 - 286.

Idem (1906), “Deeds Better than Words” En: Indian Opinion, 26 de octubre de 1906. [Republicado en la colección, Narayan, Shriman ed. Works of Mahatma Gandhi, Vol. 6, 1997].

Hunt, James D. (2005) An American Looks At Gandhi. Essays in Satyagraha, Civil Rights and Peace.capítulo 5: «Suffragettes and Satyagraha: Gandhi and the British Women's Suffrage Movemen», Promilla\& Co., Publishers in association with Bibliophile South Asia, New Delhi \& Chicago.

Käppeli, Anne-Marie (2006), “Escenarios del Feminismo”. En: Duby, Georges y Perrot, Michelle (dir.) Historia de las mujeres en Occidente. Dentro del Tomo 4 de Geneviève Fríase y Michelle Perrot (dir.) El siglo XIX. Taurus, Madrid. $4^{\mathrm{a}}$ ed. pp. 521-558 [Título original: Storiadelledonne(1990)].

López Martínez, Mario (2006), Política sin violencia. La noviolencia como humanización de la política. Uniminuto, Bogotá. [1ª edición].

Ídem (2012), “Gandhi, política y satyagraha” En: Revista científica RaXimhai. Paz, Interculturalidad y Democracia. Volumen 8 número 2, enero abril. Universidad Autónoma Indígena de México, Sinaloa, pp. 39 - 70.

Millares, Alicia (2005) “El Sufragismo” En: Amorós, Celia y De Miguel, Ana (2005), Teoría Feminista: De la Ilustración a la Globalización. De la ilustración al segundo sexo. Volumen 1. Minerva Ediciones, Madrid, pp. 245 - 293.

Palomo Cermeño, Eva (2015), Sylvia Pankhurst, sufragista y socialista. Almud, ediciones, Castilla-La Mancha.

Puleo, Alicia H. (1993), La ilustración olvidada. La polémica de los sexos en el siglo XVIII. Anthropos, Barcelona.

Pankhurst, Estelle Sylvia (1977), The Suffragette Movement. An intimate account of persons and ideals. Virago Press, Londres.

Sharp, Gene (1973), The Politics of Nonviolent Action. Porter Sargent, Boston. 
Smith, Harold L. (2013), Routledge, Londres y Nueva York. [1 ${ }^{\mathrm{a}}$ ed. 1998]

Thébaud, Françoise (1993), “La Primera Guerra Mundial: ¿La era de la mujer o el triunfo de la diferencia sexual?” En: Duby, Georges y Perrot, Michelle (dir.) Historia de las mujeres en Occidente. Dentro del Tomo 5 de Françoise Thébaud (dir.) El siglo XX. Taurus, Madrid. pp. 30-89 [Título original: Storia delle donne (1990)].

Valcárcel, Amelia (2009), Feminismo en el mundo global. Ediciones cátedra, Madrid. [1 $1^{\text {a }}$ edición, 2008].

Vidaurreta Campillo, María (1979), La guerra y la condición femenina en la sociedad industrial: el caso de Francia. Dirección General de la Juventud y Promoción Sociocultural. Madrid.

\section{Enlaces web}

Amorós, Celia, Teoría feminista. [Conferencia impartida en la Universidad Complutense de Madrid, con motivo de la celebración de 20 Aniversario del Curso de Teoría Feminista] https://www.youtube.com/ watch?v=v_xOnIGkTQ8 [consulta: 30.05.2014]

Amorós, Celia, El Feminismo de la Igualdad. [Programa "Pienso Luego Existo” de La 2 de Radio Televisión Española (RTVE) del 09-12-2011] http://www.rtve.es/television/20111209/celia-amoros-feminismo-igualdad/ 480952.shtm [consulta: 18-04-2014]

BBC radio Archive, Sylvia Pankhurst on Emmeline. The achievements of the suffragette leader are recalled by her daughter. http://www.bbc.co.uk/ archive/suffragettes/8300.shtml [Consulta: 19-01-2016]

BBC radio 4, SuffragetteSpecial. [Programa presentado por Jenni Murray que ofrece un especial sobre la lucha sufragista en Inglaterra] http:// www.bbc.co.uk/programmes/b03775ft [Consulta: 19-01-2016]

Ferrer, Sandra, La sufragista inglesa, Emmeline Pankhurst (18581928).[Blog de la autora con licencia de reconocimiento no comercial] http:/ /www.mujeresenlahistoria.com/2014/06/la-sufragista-inglesa-emmeline.html [consulta: 19-01-2016]

Independent, Women's suffrage movement: The story of Kate Harvey. [Sitio web de difusión de este diario inglés] http://www.independent.co.uk/news/ uk/this-britain/womens-suffrage-movement-the-story-of-kate-harvey516710.html [consulta: 18-01-2016]

Pankhurst, Emmeline, “Freedom or death”. En: Great speeches of the $20^{\text {th }}$. Century. [Sitio web de The guardian.com] http://www.theguardian.com/ theguardian/2007/apr/27/greatspeeches1 [Consulta: 18-01-2016] 
Sheila, Susurro de Intenciones. [Blog de la autora con licencia de reconocimiento no comercial] http://sheyehs.blogspot.com.es/p/peliculasfeministas.html [Consulta: 18-01-2016]

Spartacus Educational, Women'spilgrimage. [Sitio web de Spartacus Educational Publishers Ltd.] http://spartacus-educational.com/ Wpilgimage.htm [consulta: 20-01-2016]

Valcárcel, Amelia, Feminismo y Ciudadanía. Fundamentos Filosóficos. [Conferencia impartida el 10 de octubre de 2013 en Monterrey (México): Cátedra Alfonso Reyes del Tecnológico de Monterrey] https:// www.youtube.com/watch?v=Yell2AbX0zI [Consulta: 31-05-2014]

Recibido: 30.01.2016

Aceptado: 05.04.2016 